\title{
Endophytic fungal community succession in reproductive organs of two olive tree cultivars with contrasting anthracnose susceptibilities
}

\author{
Fátima Martins ${ }^{\mathrm{a}, \mathrm{b}}$, Cristina Cameirão a , Diogo Mina a , Jacinto Benhadi-Marín a , \\ José Alberto Pereira ${ }^{a}$, Paula Baptista ${ }^{\text {a, * }}$ \\ a Centro de Investigação de Montanha (CIMO), Instituto Politécnico de Bragança, Campus de Santa Apolónia, 5300-253, Bragança, Portugal \\ ${ }^{\mathrm{b}}$ Department of Engineering and Agricultural Science - University of Leon, Avda. Portugal $N^{\circ} 41,24071$, León, Spain
}

\section{A R T I C L E I N F O}

\section{Article history:}

Received 29 March 2020

Received in revised form

18 September 2020

Accepted 22 September 2020

Available online 17 October 2020

Corresponding Editor: James White Jr

\section{Keywords:}

Colletotrichum

Olea europaea

Inflorescences

Fruits

Phenological stages

Endophytes

\begin{abstract}
A B S T R A C T
The factors shaping endophytic fungal assemblages in reproductive organs have been less evaluated than in vegetative organs. Here, the temporal dynamics of fungal endophytes in inflorescences and fruits of olive tree cultivars with contrasting anthracnose susceptibilities was assessed, starting before flowers open until fruit ripening. Fungal diversity assessed by rRNA sequencing of cultivable isolates revealed a higher richness and abundance of endophytes in inflorescences than in fruits. Endophytes from Sordariomycetes were dominant in inflorescences, while in fruits they were from Dothideomycetes. The overall assemblages of inflorescences and fruits were shaped mainly by the plant organ, followed by the phenological stage and lastly, by the plant cultivar. The importance of cultivar as a shaping factor varied according to the plant organ, being only significant in inflorescence-associated endophytes. A set of fungal taxa were positively associated with a particular cultivar and phenological stage, likely contributing to the plant anthracnose resistance.
\end{abstract}

๑) 2020 Elsevier Ltd and British Mycological Society. All rights reserved.

\section{Introduction}

Plants are associated with a great diversity of fungi that live within their tissues as endophytes (Zhang et al., 2019). These fungi play an important role in host plant fitness, by protecting them from abiotic and biotic stresses, such as pathogenic microorganisms and insect pests, and by improving plant growth (Zhang et al., 2019). Because of their recognized importance, studies on fungal endophytes and their interaction with the host plant have recently produced a growing body of literature (Khare et al., 2018). However, we are yet to know what forces determine specific fungal community assemblages, in particular in woody perennials (Compant et al., 2016). Endophytic fungal surveys conducted in woody perennials over recent years showed that plant organ is a significant factor in shaping endophytic fungal assemblage (e.g. Moricca et al., 2012; Abdelfattah et al., 2015; Gomes et al., 2018; Singh et al., 2018; Ren et al., 2019). In general, the main plant tissues that have been analyzed in these studies were vegetative organs, such as leaves,

\footnotetext{
* Corresponding author.

E-mail addresses: pbaptista@ipb.pt, pbaptista@ipb.pt (P. Baptista).
}

twigs, barks, stems and roots, and only a few studies have looked for fungal endophytes in reproductive organs (e.g. flowers or fruits). Furthermore, little research has been performed on the monitoring of endophytic fungal communities of reproductive organs over their development, ranging from flowering to fruit ripening (Abdelfattah et al., 2015).

Plant genetics (at species or genotype level) also control endophytic fungal community composition of woody perennials (e.g. Moricca et al., 2012; Bálint et al., 2013; Qian et al., 2018). However, this plant effect has been mostly recognized within endophytic fungal communities of vegetative organs (Moricca et al., 2012; Bálint et al., 2013; Qian et al., 2018), while the ones colonizing reproductive organs have not been studied yet in detail. Such knowledge could help to identify whether the differences in host susceptibility to fruit diseases is somehow linked with the host plant capacity to recruit specific endophytic fungal species. The ability of plants to recruit protective microorganisms to suppress pathogens has already been reported in the rhizosphere (Berendsen et al., 2012). To the best of our knowledge, such plant effects on the endophytic fungal community inhabiting the plant above ground parts are largely unknown.

Olive tree (Olea europaea) is one of the most economically 
important oil-producing crops in many countries of the world, particularly in the Mediterranean basin countries (IOC, 2019). In most of these countries, the anthracnose (a disease caused by Colletotrichum spp.) is a key constraint to olive production through its effects on leaves, twigs, branches, and mostly on olives (Cacciola et al., 2012). The infection process in fruits is believed to start in flowers, remaining quiescent until the ripening of the fruits (Sergeeva et al., 2008), where symptoms have been most noted (Cacciola et al., 2012). So far, no anthracnose-resistant olive tree genotypes have been found, but there are cultivars that are more prone to infection than others (Moral et al., 2017). For example, among the most important Portuguese commercial olive cultivars, 'Cobrançosa' is less susceptible to anthracnose than the cv. 'Madural' (unpublished results). Here, the compositional differences in the endophytic fungal communities of different plant reproductive organs (inflorescence and fruit) of two olive cultivars with different susceptibilities to olive anthracnose ('Cobrançosa' and 'Madural') were investigated, over inflorescence and fruit development. Specifically, this study aims to decipher: (i) the relative contribution of plant organ (inflorescence and fruit) and host genotype (at cultivar level) on endophytic fungal assembly; (ii) patterns of plant-endophyte association over different time points of inflorescence and fruit development; and (iii) whether the differences in susceptibility of the cultivars to anthracnose may be related to the endophytic community naturally occurring in inflorescence and fruit. In this study we used a culture dependent PCRbased identification approach to characterize the endophytic fungal communities, with the aim to further exploit and use these strains to improve resistance of olive tree to anthracnose disease.

\section{Materials and methods}

\subsection{Sample collection}

The plant sampling was conducted from May to November 2017, in one olive grove located in Mirandela (northeast of Portugal) at coordinates $41^{\circ} 3308^{\prime \prime} \mathrm{N}, 7^{\circ} 07^{\prime} 24^{\prime \prime} \mathrm{W}$. This grove is mainly composed of olive trees of cultivars 'Cobrançosa' and 'Madural', spaced $7 \mathrm{~m}$ from each other, and is approximately $60 \mathrm{y}$ old. These two cultivars are considered resistant and susceptible, respectively, by the local olive growers. This grove has been managed through integrated production guidelines (Malavolta and Perdikis, 2018). Only one treatment with copper based products was performed in the middle of February for fungal diseases control and no other pesticides were used. Tillage was performed three times per year, the first at the end of March, the second at the beginning of May and the third at the end of September. Pruning was performed every $2-3$ y and no irrigation was done. From each cultivar, seven olive trees were randomly selected and used to collect inflorescence and fruit samples over different phenological stages. The collection of inflorescences was performed during inflorescence development [i.e. on flower cluster development (D) - from 15th to 25th May, and on flower cluster totally expanded (E) - from 30th May to 10th June] and flowering [i.e. flowers open (F) - from 15th to 25 th June, and petals fallen or faded $(G)$ - from 5th to 15th July], whereas fruit collection was at stone hardening $(\mathrm{H})-$ from 30th July to 15th August, and ripening [i.e. beginning of maturation (I) from 2nd to 23rd September, and maturation of fruit $(\mathrm{J})$ - from 6 th October to 23rd November] (Sanz-Cortés et al., 2002) (Fig. 1). The maturity stage of the collected fruits was estimated by a maturity index (MI), which is based on both skin and flesh fruit color, and ranged in a scale from 0 (olives with intense green color) to 7 (olives with black skin and flesh purple to the pit) (Hermoso et al., 2001). The collected fruits encompassed three MI, namely MI 2 (epidermis shows red spots in less than half the fruit), 3 (epidermis is red or purple in more than half the fruit) and 4 (black epidermis and white pulp). At each time point of sampling, 25 asymptomatic inflorescence or fruit samples per tree were collected, around the perimeter of the tree at the operator height and placed directly into sterile bags. The samples collected were transported to the laboratory and stored at $4{ }^{\circ} \mathrm{C}$ until isolation of the endophytic fungi, which was carried out within 1 week.

\subsection{Isolation of endophytic fungi}

The inflorescences and fruits collected were rinsed with distilled water, and then surface sterilized through sequential immersion in $3 \%(\mathrm{v} / \mathrm{v})$ sodium hypochlorite for $1 \mathrm{~min}$ (for inflorescences) or $2 \mathrm{~min}$ (for fruits), $70 \%(\mathrm{v} / \mathrm{v})$ ethanol for $1 \mathrm{~min}$ and rinsed three times with sterile distilled water ( 1 min each). The efficiency of the surface sterilization had previously been optimized for inflorescence and fruit samples. In particular, different combination and duration of exposure to ethanol and sodium hypochlorite were tested. The protocol used was shown to be sensitive enough to allow recovery of the endophytes and to be the most effective in eliminating epiphytes from the plant surface. After surface sterilization, one flower per inflorescence and single fruits were cut into ca. $2 \mathrm{~mm}$ pieces. Six pieces per organ were plated onto potato dextrose agar (Difco, PDA) medium supplemented with $0.01 \%(\mathrm{w} / \mathrm{v}$ ) chloramphenicol (Oxoid, Basingstoke, Hampshire, UK) in a 9-cm-diameter plate. For each sampling date, a total of 2100 segments of flowers were inoculated [ 2 cultivars $\times 7$ olive trees (replicates) x 25 flowers (one flower per inflorescence, representing one sample) x 6 segments per flower (encompassing one sample)], making a total of 8400 segments of flowers in the whole work (2100 segments $x 4$ sampling dates). For fruits, a total of 2100 segments were assayed in each sampling date [ 2 cultivars $x 7$ olive trees (replicates) $\times 25$ fruits (each representing one sample) $\times 6$ segments per fruit (encompassing one sample)], making a total of 6300 fruit segments in the whole study (2100 fruit segments $x 3$ sampling dates). All plates (25 plates per tree in each sampling date) were incubated at $25 \pm 2{ }^{\circ} \mathrm{C}$ in the dark and were observed daily. The fungi growing out of the tissue segments were recorded as endophytes and were sub-cultured on individual PDA plates to obtain pure isolates for subsequent identification. Pure cultures of each isolate were deposited in the culture collection of the Mountain Research Center (CIMO), School of Agriculture Polytechnic Institute of Bragança.

\subsection{Identification of fungal isolates}

The isolates obtained were grouped according to their morphological characteristics (colony morphology, hyphae, spores and reproductive structures). For each morphotype, two representative isolates were selected for molecular identification, by using the internal transcribed spacer (ITS) region of the nuclear ribosomal DNA (rRNA). Fungal DNA was extracted using REDExtract-N-Amp ${ }^{\mathrm{TM}}$ Plant PCR kit (Sigma, Poole, UK) following manufacturer's instructions. The PCR reactions, with the pair of primers ITS1 and ITS4 (White et al., 1990), were performed using the same DNA extraction kit following the manufacturer's instructions, in the MyCycler thermal cycler (Bio-Rad). The amplified products $(\sim 650$ bp) were purified and sequenced using Macrogen Inc. services (Madrid, Spain). The DNA sequences obtained were assembled and aligned using the SeqMan DNASTAR software (Lasergene, DNASTAR Inc., Madison) in order to delimit ITS1, the $5.8 \mathrm{~S}$ gene and ITS2 regions. Once trimmed, ITS sequences were compared against reference sequences deposited in both UNITE (http://unite.ut.ee/) and GenBank (National Center for Biotechnology Information; https:// blast.ncbi.nlm.nih.gov/Blast.cgi) using the Nucleotide Basic Local Alignment Search Tool (BLASTn) with and without the 'Sequences 


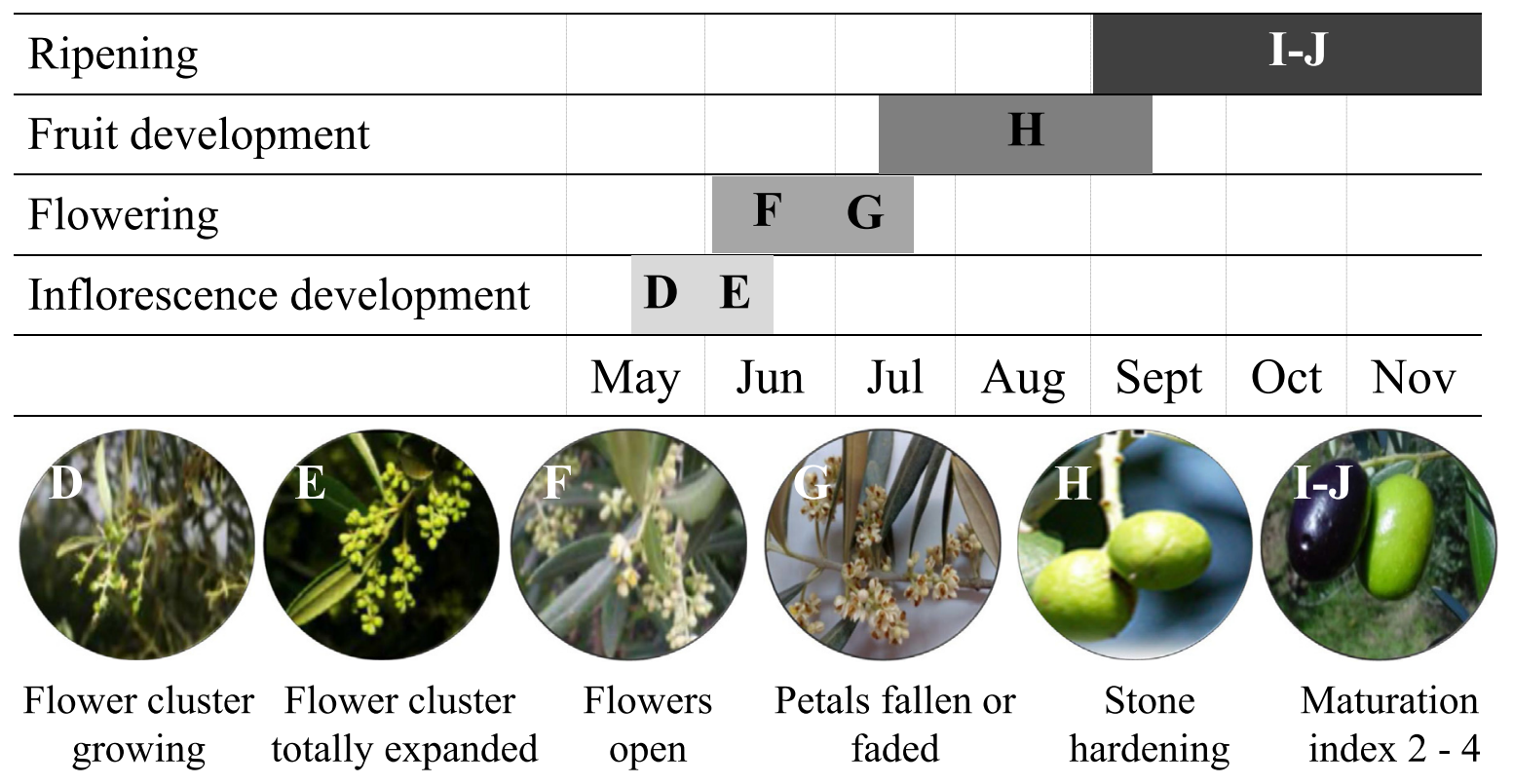

Fig. 1. Phenological growth stages of the olive tree cvs. 'Cobrançosa' and 'Madural' in which the sampling of flowers and fruits was performed from May to November 2017. Phenological stages (from D to J) were defined by Sanz-Cortés et al. (2002) while maturation index of fruits was defined by Hermoso et al. (2001) as MI 2 (epidermis shows red spots in less than half the fruit), 3 (epidermis is red or purple in more than half the fruit) and 4 (black epidermis and white pulp).

from type material' selected. Based on the results of Vu et al. (2019), it was decided to use in the BLAST search a query coverage of $\geq 80 \%$ and $\geq 96-100 \%$ sequence similarity for assigning a species name in one of the following categories: (i) positive species identification for sequence similarity of $100 \%$; (ii) possibly this species (suffix cf.) for sequence similarity of 99\%; and (iii) certainly not this species, but taxonomic closely related (suffix aff.) for sequence similarity of 96-98\%. Taxonomic classification at genus level was adopted when equal BLAST top score similarity values (ranging from 96 to 100\%) were obtained for different species of the same genus or BLAST top score inferior to $96 \%$, but with several species belonging to the same genus. Classification at the family, order and class levels was adopted when BLAST top score similarity values were $<96 \%$ for several fungi, all from the same family, order or class, respectively. The "distance tree of results" option on the BLAST results page was used to determine misidentification for deposited sequences, when BLAST results were equally high for several species. Current taxonomic name of the fungi obtained from GenBank were then identified in Index Fungorum (www.indexfungorum.org) and adopted in this work.

\subsection{Abundance and diversity of fungal endophytes}

Abundance and diversity of fungal endophytes detected in inflorescence and fruit over different phenological stages were quantified as frequency of colonization (FC, \%), relative abundance (RA, \%), species richness, abundance and diversity index. FC (\%) was estimated as the total number of plant tissue segments colonized by fungal endophytes divided by the total number of all incubated segments surveyed for each phenological stage. RA (\%) was determined at genus level by dividing the total number of isolates of a genus by the total number of isolates of all fungal genera identified in each phenological stage. Species richness (average number of taxa per tree) and abundance (average number of isolates per tree) were estimated considering each individual tree as a sample unit, for statistical analysis purposes. The diversity was estimated by computing Shannon-Wiener $(\mathrm{H})$ index in Species Diversity and Richness v. 4.0 software (Seaby and Henderson, 2006), and the results were presented as the mean of individual host tree or as the total number. To determine differences in fungal richness, abundance and diversity among phenological stages, a one-way analysis of variance (one-way ANOVA) was performed, followed by the posthoc multi-comparison Tukey's test to identify statistically significant differences $(\mathrm{p}<0.05)$, using SPSS v.18 software. Normality and homogeneity of the data were evaluated by Shapiro-Wilk test and Levene test, respectively. The one-way ANOVA results are shown in Table S1 (Supplementary material).

\subsection{Data analysis}

Generalized linear mixed models (GLMMs) were used to test effects of olive cultivar ('Cobrançosa' and 'Madural'), plant organ (inflorescence and fruit), phenological stage, and their interaction on fungal abundance and richness. These models were developed 
in R ( R Core Team, 2018) following Zuur et al. (2009). Since the number of levels of samples collected were different for inflorescences and fruits, its effect was modelled independently of the organ. Both the abundance and richness of fungi were counts; thus the Poisson distribution was used for each model as:

Abundance $_{i s} \sim \operatorname{Poisson}\left(\mu_{i s}\right) \Rightarrow \mathrm{E}\left(\right.$ Abundance $\left._{i s}\right) \sim \mu_{\text {is }}$

$$
\begin{aligned}
& \eta_{\text {is }}=\alpha+\beta_{1} \times \text { Cultivar }_{\text {is }}+\beta_{2} \times \text { Organ }_{\text {is }}+\beta 3 \\
& \quad \times \text { Cultivar }_{\text {is }}: \operatorname{Organ}_{\text {is }}+\mathrm{a}_{\mathrm{i}}
\end{aligned}
$$

$$
\begin{aligned}
& \eta_{\text {is }}=\alpha+\beta_{1} \times \text { Cultivar }_{\text {is }}+\beta_{2} \times \text { Index }_{\text {is }}+\beta_{3} \\
& \quad \times \text { Cultivar }_{\text {is }}: \text { Index }_{\mathrm{is}}+\mathrm{a}_{\mathrm{i}} \\
& a_{i} \sim N\left(0, \sigma^{2}{ }_{a}\right) ; \log \left(\mu_{i s}\right)=\eta_{i s} \text { and } \\
& \text { Richness }_{i s} \sim \operatorname{Poisson}\left(\mu_{i s}\right) \Rightarrow \mathrm{E}\left(\text { Richness }_{i s}\right) \sim \mu_{i s}
\end{aligned}
$$$$
\eta_{\text {is }}=\alpha+\beta_{1} \times \text { Cultivar }_{\text {is }}+\beta_{2} \times \text { Organ }_{\text {is }}+\beta 3
$$$$
\times \text { Cultivar }_{\text {is }}: \operatorname{Organ}_{\text {is }}+\mathrm{a}_{\mathrm{i}}
$$

$\eta_{\text {is }}=\alpha+\beta_{1} \times$ Cultivar $_{\text {is }}+\beta_{2} \times$ Index $_{\text {is }}+\beta_{3}$

$$
\times \text { Cultivar }_{\text {is }}: \text { Index }_{\text {is }}+\mathrm{a}_{\mathrm{i}}
$$

$a_{i} \sim N\left(0, \sigma^{2}{ }_{a}\right) ; \log \left(\mu_{i s}\right)=\eta_{i s}$ where Cultivar ${ }_{i s}$ represents the effect

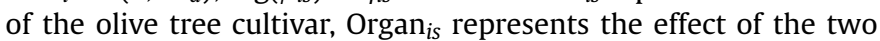
olive organs considered, Cultivar ${ }_{i s}$ : Organ $_{\text {is }}$ and Cultivar $_{i s}$ : Index represent the interaction term between the two corresponding drivers, respectively, and $a_{i}$ represents the random effect term for the olive tree.

Non-metric multidimensional scaling (NMDS) was carried out to explore the similarity of fungal community composition among olive tree cultivars, plant organ and phenological stages. NMDS was performed using Bray-Curtis dissimilarity matrix (Bray and Curtis, 1957), generated with ITS genotype abundance data with the values square root transformed to limit the influence of abundant fungal genotypes. One-way analysis of similarity (ANOSIM) was then done to test for significant differences in dissimilarities of the fungal community groupings obtained in NMDS ordination, using the same Bray-Curtis distance matrices. These analyses were performed using the Community Analysis Package v. 5.0 (Seaby and Henderson, 2014).

To estimate the percentage of variation of endophytic fungal community explained by olive cultivar, plant organ and phenological stage, a variation partitioning analysis was performed with the function varpart (based on redundancy analysis, RDA) in the vegan $\mathrm{R}$ package (Oksanen et al., 2018).

Co-inertia analysis (CIA) was used to explore the relationships between olive cultivar or phenological stage variables and endophytic fungal assemblage in inflorescences and fruits of olive tree. This analysis, which was performed by using fungal genus abundance matrices, also helped to identify fungal genera that correlate with particular olive cultivars or phenological stages. The CIA was performed in the R statistical environment ( $\mathrm{R}$ Core Team, 2018), by using coinertia function (to do the analysis) and table. value function (to visualize the results in a factorial map), both available in the ade4 package (Dray and Dufour, 2007). The statistical significance of co-inertia was evaluated with a Monte Carlo permutation test $(10,000$ simulations), by using randtest. coinertia function available in the same $R$ package.

To identify fungal taxa that are characteristic of each olive cultivar and phenological stage, an indicator value (IndVal) analysis (Dufrêne and Legendre, 1997) was performed, using the function multipatt from indicspecies $\mathrm{R}$ package (Cáceres et al., 2012). This method identifies indicator species based on their specificity (i.e. uniqueness) to a particular habitat (A) and their frequency in that habitat (B). The IndVal ranges from 0 to 1 with higher values representing higher indicative power, and significant $(\mathrm{p}<0.05)$ IndVal values of greater than 0.5 indicate species that are deemed characteristic of a group (Cáceres et al., 2012).

\section{Results}

Across all the plant tissues collected in both cultivars, a total of 466 endophytic isolates belonging to 109 fungal taxa (i.e., ITS genotypes), being 84 taxa identified at the inflorescence level and 42 taxa at the fruit level, were obtained (Table S1). The 109 taxa were assigned to 34 species, 48 genera and 35 families (Fig. S1). Most of the fungal isolates belonged to Ascomycota phylum (99.8\% of the total isolates), and in particular to families Xylariaceae (26\%) and Pleosporaceae (14\%), and genera Biscogniauxia (22\%), Alternaria (10\%) and Cladosporium (9\%). Among Basidiomycota (0.2\% of the total fungal isolates), members only belonging to the Polyporaceae family and Coriolopsis genus were found. Overall, the colonization rate of endophytic fungi was higher in inflorescence (4.2\%) than in fruit (1.8\%) (Table S1).

\subsection{Diversity and composition of endophytes differ between cultivars}

The olive cultivars studied markedly differed in fungal diversity and abundance (Table S1). Within endophytic communities inhabiting inflorescences, altogether the results indicated that anthracnose-susceptible cv. 'Madural' had significantly higher ( $p<0.05$ ) fungal colonization rate (up to 3.2-fold), abundance (up to 3.1 -fold), richness (up to 3.0-fold) and species diversity (up to 2.3-fold) than anthracnose-resistant cv. 'Cobrançosa'. The same pattern was observed within the endophytic community colonizing fruits. Overall, fruits of cv. 'Madural' had significantly $(\mathrm{p}<0.05)$ higher colonization rate (up to 1.1 -fold), abundance (up to 1.3-fold), richness (up to 1.5 -fold) and diversity (up to 1.8 -fold) of fungal endophytes than cv. 'Cobrançosa'. These results were corroborated by generalized linear mixed model (GLMM), which showed a significant $(p<0.01)$ effect of olive cultivar on the abundance and richness of fungal endophytes in inflorescence and fruit (Table S2).

NMDS plots, based on Bray-Curtis index, and ANOSIM analysis showed that endophytic community composition differed among olive tree cultivars (global $\mathrm{R}=0.59, \mathrm{p}=0.001$ ), this dissimilarity being greater for inflorescence $(R=0.41, p=0.001)$ than for fruit ( $\mathrm{R}=0.18, \mathrm{p}=0.001$ ) (Fig. 2). In fact, only 29 fungal taxa out of the 109 recovered in this study were isolated in both cultivars; 26 fungal taxa were isolated only in cv. 'Cobrançosa' and 54 were recovered only in cv. 'Madural' (Fig. S2). A higher percentage of taxa specific to one cultivar were observed in inflorescences $(84.5 \%)$ when compared to fruits (around 71.4\%).

\subsection{Diversity and composition of endophytes in reproductive organs over different phenological stages}

A GLMM was used to explore the relationship between the explanatory (organ and phenological stage) and response (fungal abundance and richness) variables (Fig. 3; Table S2). In this analysis the phenological stage corresponding to the fruit development $(\mathrm{H})$ was not included, since no fungal growth was obtained in the assayed fruit explants. GLMM results indicated that the plant organ (inflorescence and fruit) affected significantly $(\mathrm{p}<0.01)$ the total endophytic fungal abundance and richness (Table S2). Overall, the abundance and richness of fungal endophytes were greater in inflorescences than in fruits, for both olive tree cultivars, and in particular for cv. 'Madural' (Fig. 3). Host phenology has similarly 
Inflorescence

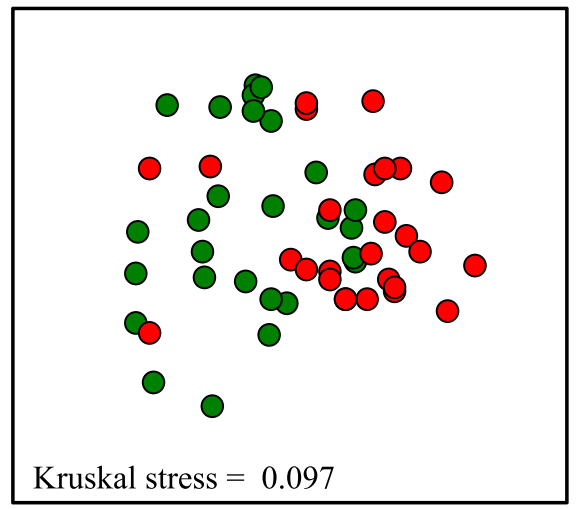

cv. Cobrançosa
Fruit

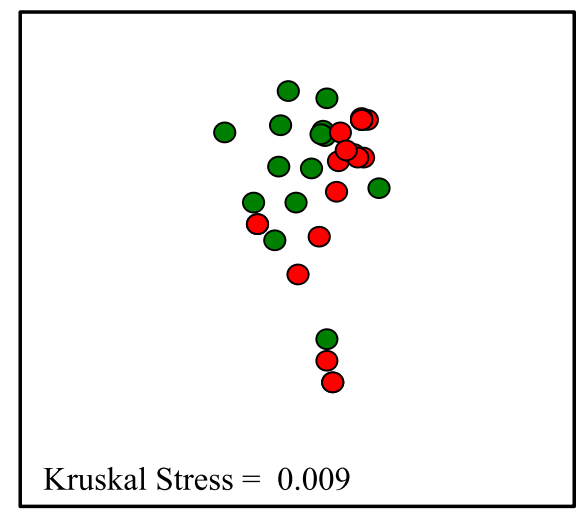

cv. Madural

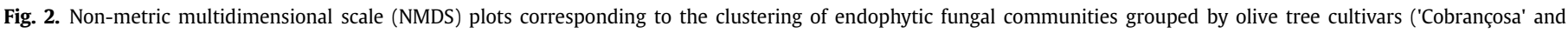

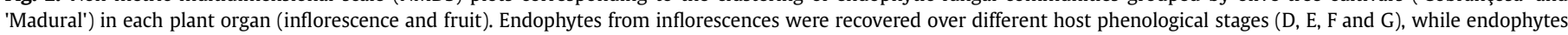

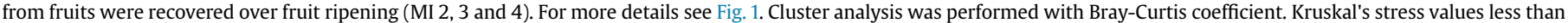
0.2 represent good ordination plots.
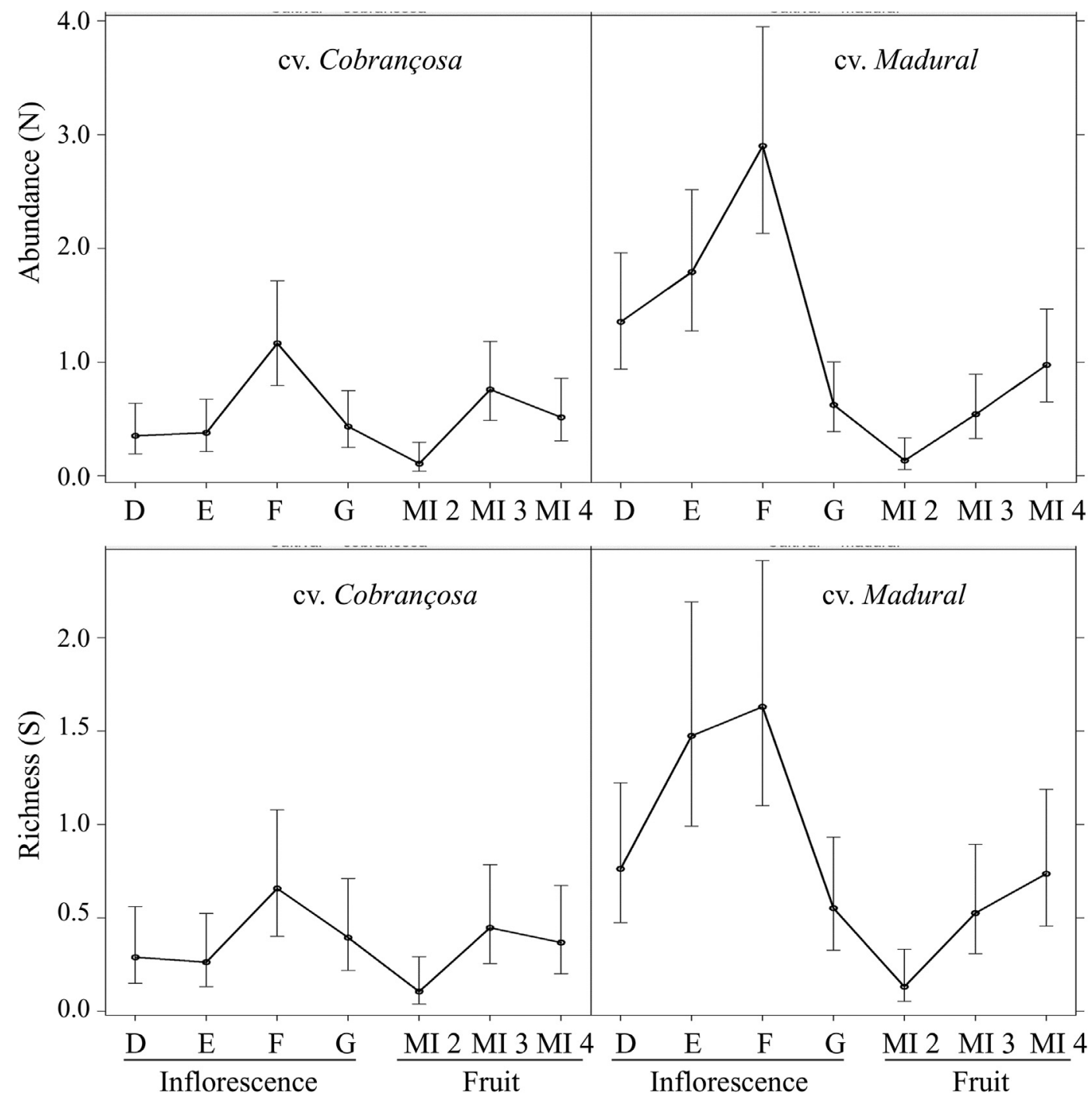

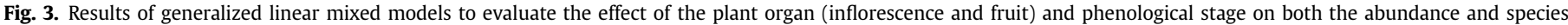

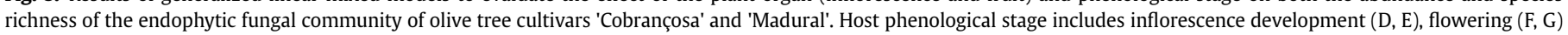
and fruit ripening (MI 2, 3, 4). For more details see Fig. 1. 
affected significantly ( $\mathrm{p}<0.01$ ) both fungal abundance and richness in inflorescence and fruit. In cv. 'Cobrançosa', both fungal abundance and richness increase over inflorescence development reaching a significant $(\mathrm{p}<0.001)$ peak on the flowering, specifically in the stage when flowers are open - $\mathrm{F}$ (an increase up to 3.2- and 2.3-fold, respectively). Afterwards, the fungal abundance and richness dropped until the starting of fruit maturation, and then increased over the fruit maturation reaching a significant $(\mathrm{p}<0.001)$ peak when fruit epidermis is red or purple in more than half the fruit - MI 3 (an increase up to 5.0 and 4.0-fold, respectively). The variation of both fungal abundance and richness on reproductive organs of cv. 'Madural' over the different phenological stages followed a similar trend. The only difference found between these two cultivars was at the level of the fruit. In contrast to cv. 'Cobrançosa', both fungal abundance and richness on fruits of cv. 'Madural' increase significantly ( $\mathrm{p}<0.001$ ) over fruit maturation (up to 7.2 and 6.5-fold, respectively).

The NMDS ordination, based on Bray-Curtis index, revealed that each organ and phenological stage formed an individual cluster (Fig. 4). The ANOSIM test confirmed the significant differences in the whole fungal community structures among plant organs (global $\mathrm{R}=0.85, \mathrm{p}=0.001$ ) and phenological stages (global $\mathrm{R}=0.50$, $\mathrm{p}=0.001)$. These differences were greater in cv. 'Madural' $(\mathrm{R}=0.86$ and $\mathrm{R}=0.69, \mathrm{p}=0.001$, for plant organ and phenological stage, respectively) than in cv. 'Cobrançosa' ( $R=0.52$ and $R=0.67$, $\mathrm{p}=0.001$, respectively). In particular, inflorescences had different fungal communities across the phenological stages (Global $\mathrm{R}=0.41$, $\mathrm{p}=0.001$ ). The endophytic community colonizing this organ displayed the greatest differentiation among phenological stage $G$ (petals fallen or faded) and $F$ (flowers open) $(R=0.84$ and $R=0.93$, $\mathrm{p}=0.001$, for cvs. 'Madural' and 'Cobrançosa', respectively) or $\mathrm{D}$ (flower cluster growing) $(\mathrm{R}=0.86, \mathrm{p}=0.001$, for $\mathrm{cv}$. 'Madural') (Table S3). Some of the most abundant genera varied during the different phenological stages of inflorescences, which could account for the differences found in fungal composition among stages $\mathrm{G}$ and $\mathrm{F}$ or D (Fig. 5). For instance, Biscogniauxia genus that was isolated preferentially in F and D stages, disappeared in stage $G$ whereas other genera, such as Cladosporium, were the most frequent (Fig. 5). In addition, endophytic fungi of twenty-two genera, which appeared in stage $F$ and $D$, disappeared in stage $G$, contrasting with specific genera only found in stage $G$
(Pyrenophora) (Fig. 5). In contrast to inflorescences, fungal communities' composition of fruits was similar among the different maturation indexes (Global $\mathrm{R}=0.21, \mathrm{p}=0.001$ ). Despite this, there were significant differences between some pairs of MI, with the strongest separation occurring between the MI 2 and MI 4 $(\mathrm{R}=0.67, \mathrm{p}=0.001$, for cv. 'Cobrançosa'; $\mathrm{R}=0.92, \mathrm{p}=0.001$, for $\mathrm{cv}$. 'Madural') or MI 3 ( $\mathrm{R}=0.69, \mathrm{p}=0.001$, for $\mathrm{cv}$. 'Cobrançosa') (Table S3). The most abundant genera varied over fruit ripening (Fig. 5). For instances, Pyrenochaeta, Fusarium and Ochrocladosporium were most abundant in MI 2, while Cladosporium, Alternaria and Neofabraea were richest in MI 3 and 4. There is only one genus (Fusarium) shared between MI 2 and MI 3 or 4, which could also account for the differences found in the fungal communities among MI.

\subsection{Plant organ and phenological stage are the most important factors for shaping the fungal community}

Overall, plant organ $(\mathrm{F}=2.52, \mathrm{p}=0.005)$, phenological stage $(\mathrm{F}=1.91, \mathrm{p}=0.005)$ and to a lesser extent the cultivar $(\mathrm{F}=1.56$, $\mathrm{p}=0.010)$, significantly influenced the structure of the entire fungal community, explaining $5.9,5.0$ and $0.9 \%$ of the variation in their composition, respectively. Variance partitioning analysis applied to each organ showed that endophytes-associated with inflorescences were significantly affected by both phenological stage $(\mathrm{F}=1.49, \mathrm{p}=0.005)$ and cultivar $(\mathrm{F}=1.55, \mathrm{p}=0.005)$, explaining $11.8 \%$ and $1.6 \%$ of composition variation, respectively. In contrast, the endophytic assemblage of fruits was not affected by the cultivar $(\mathrm{F}=1.11, \mathrm{p}=0.165)$, but the phenological stage exerted a significant effect $(\mathrm{F}=1.42, \mathrm{p}=0.005)$, explaining $5.3 \%$ of endophytic composition variation.

\subsection{Cultivar and phenological stage preference of endophytic fungi}

Co-inertia analysis was used to find relationships between endophytic fungi assemblage and their olive cultivar or phenological stage, in inflorescence and fruit (Fig. 6). This analysis was to identify specific fungal genera associated with each olive cultivar and phenological stage, and to elucidate their potential role in cultivar differences in anthracnose disease susceptibility. At the level of inflorescence, the genera with the highest positive cv. Cobrançosa

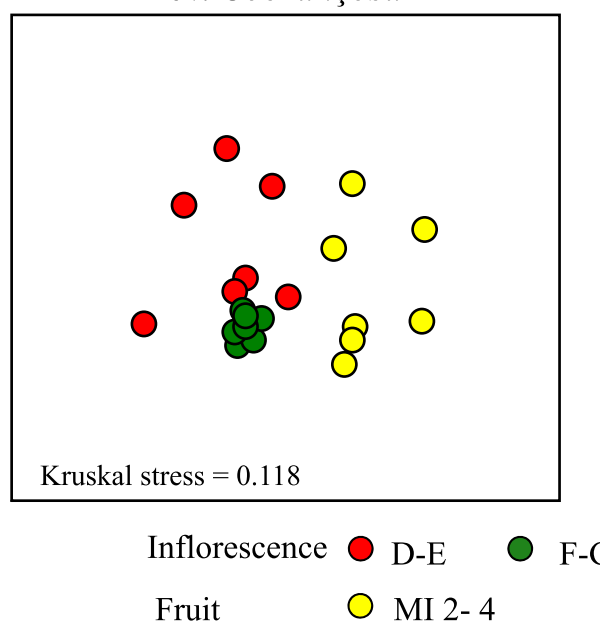

F-G cv. Madural

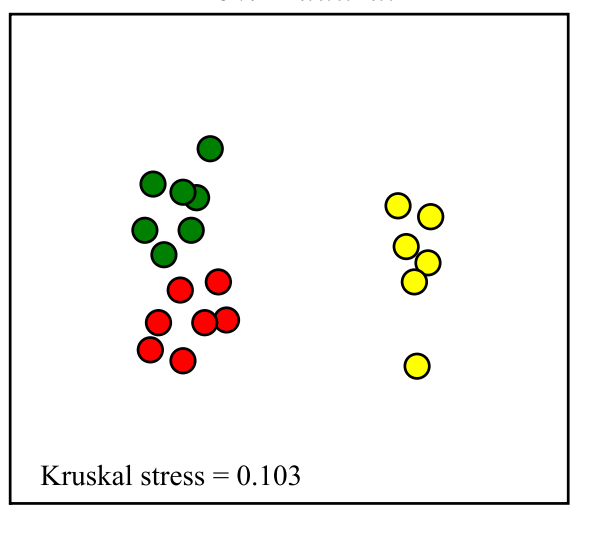

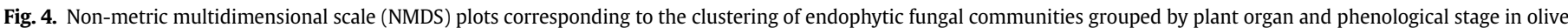

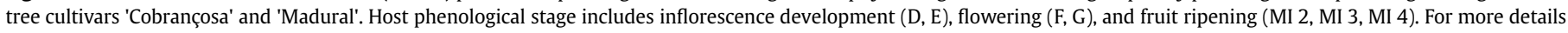
see Fig. 1. Kruskal's stress values less than 0.2 represent good ordination plots. 
cv. Cobrançosa

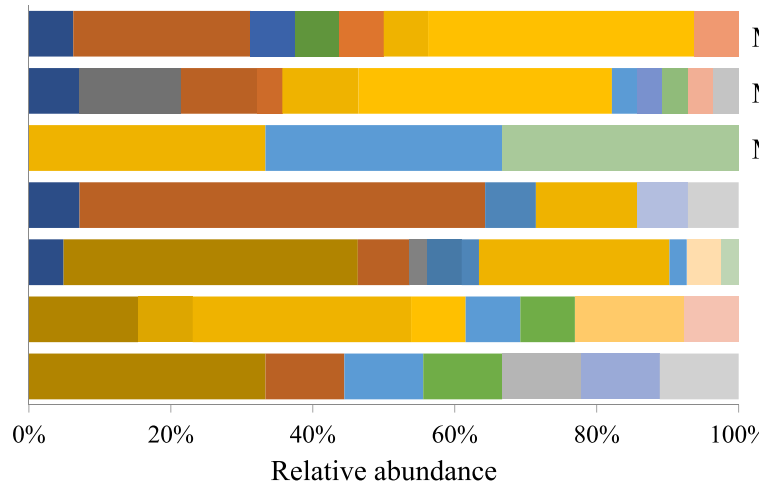

- Alternaria
- Chaetomium
- Coniochaeta
- Desmazierella
Eudarluca
- Morchella
- Parastagonospora
Praetumpfia
Pseudoplectania
Tricharina

- Aspergillus
- Cladosporium
Coniothyrium
Endoconidioma
Kalmusia
Neofabraea
Phaeosphaeria
Pseudocercospora
Pyrenophora
Xylaria

cv. Madural

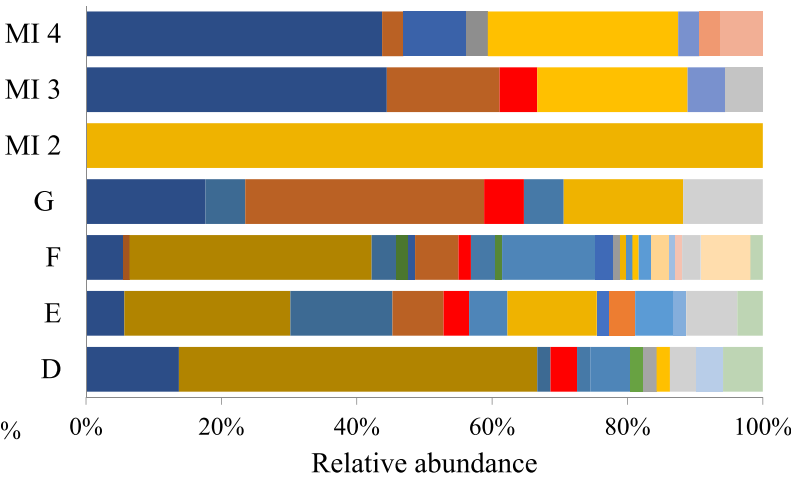

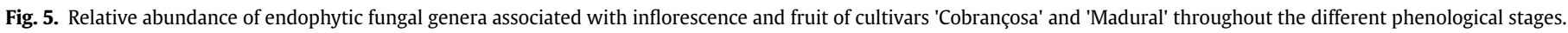
Host phenological stage includes inflorescence development (D, E), flowering (F, G), and fruit ripening (MI 2, MI 3, MI 4). For more details see Fig. 1.

correlation with cv. 'Madural' were Biscogniauxia, Botrytis, Diaporthe, Alternaria, Colletotrichum and Stemphylium, while Paraconiothyrium spp. showed the strongest positive correlation with cv. 'Cobrançosa' (Fig. 6A). The phenological stages were mostly differentiated by Tricharina, Biscogniauxia, Diaporthe and Coniochaeta, which were positively related with the stage of flowers opening. Within the endophytic community of fruits, there was a set of fungal genera highly positively associated either with cv. 'Cobrançosa' (Aspergillus, Fusarium and Ochrocladosporium) or with cv. 'Madural' (Alternaria, Coniothyrium and Colletotrichum) (Fig. 6B). The maturation indexes were mostly differentiated by Coniothyrium and Pyrenochaeta, which were positively correlated with MI 4 and MI 2, respectively. The fungal genera Pseudophaeomoniella and Aspergillus were linked with MI 3.

Species indicator analyses were further used to identify which fungal taxa best characterized each olive cultivar (and their underlying susceptibility to anthracnose disease). Results revealed thirteen indicator taxa of cv. 'Madural' (eleven at the inflorescence level and two at the fruit level), and one indicator taxa of cv. 'Cobrançosa' (at fruit level) (IndVal > 0.560, p < 0.05; Table S4). From these, the best indicator fungal taxa that characterized cv. 'Madural' were Tricharina sp. MF20 (IndVal = 0.926), Diaporthe sp. FC5 (IndVal $=0.826)$ and Alternaria sp. AZM1 (IndVal $=0.772)$. In cv. 'Cobrançosa', the only species indicator was Fusarium aff. solani $($ IndVal $=0.614)$.

\section{Discussion}

The endophytic fungal community associated with reproductive organs has been rarely studied, in particular in woody plant species. In this work, we investigated the cultivable endophytic fungal community associated with inflorescences and fruits of two olive tree cultivars, with contrasting susceptibilities to olive anthracnose. It is well-known that the cultivable approach has some limitations mainly related to the underestimation of the microbial composition in samples (Wu et al., 2019). However, it has been demonstrated that all endophytic fungal genera frequently detected by the culture-dependent approach were also detected by the cultureindependent (e.g., next generation sequencing) method (Dissanayake et al., 2018). We found that inflorescences and fruits of olive trees were colonized mostly by Ascomycota within the Sordariomycetes and Dothideomycetes. This result was consistent with another study using high-throughput sequencing of the fungal microbiome in the same olive tree plant organs (Abdelfattah et al., 2015). Hence, it is likely that these particular fungi were dominant in olive tree reproductive organs and can be considered as the key classes (Sordariomycetes for flowers and Dothideomycetes for fruits). Curiously, the present study revealed that members of the Xylariaceae were the most abundant in reproductive organs, while previous studies that focused on endophytes isolated from vegetative organs of olive trees reported Leptosphaeriaceae, Pleosporaceae, Pyronemataceae, Trichocomaceae, and Diaporthaceae as the most abundant (Gomes et al., 2018). Thus, it is likely that endophytic community composition of reproductive organs could be different from that of vegetative organs of olive trees.

The effect of the host genotype in shaping the composition of fungal endophytic communities has been reported mostly in vegetative organs (e.g. Moricca et al., 2012; Bálint et al., 2013; Qian et al., 2018). Here, although the plant cultivar was not identified as the main driver of fungal assemblage in reproductive organs, the results from the variation partitioning analysis suggest host control over fungal communities in inflorescences. Thus, as previously reported for vegetative organs (Moricca et al., 2012; Bálint et al., 2013; Qian et al., 2018), in inflorescences the host plant seems to selectively recruit and promote the growth of certain fungal species. A similar host-cultivar effect on endophytic fungal structure was reported for flowers of Pinggu peach trees (Ren et al., 2019). It is still not clear what mechanisms lead to differences in the endophytic fungal community structure among host genotypes (Bálint et al., 
A
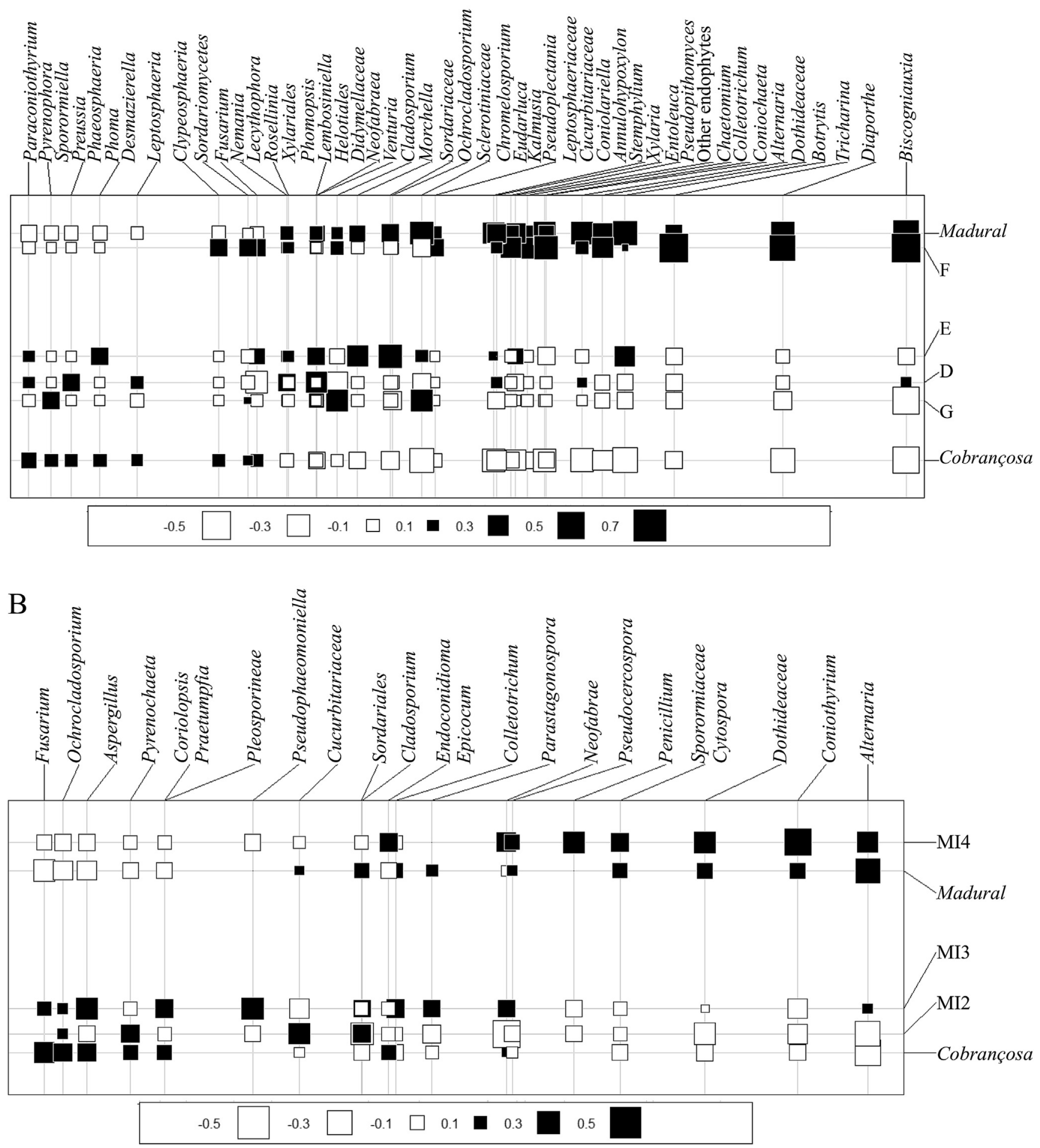

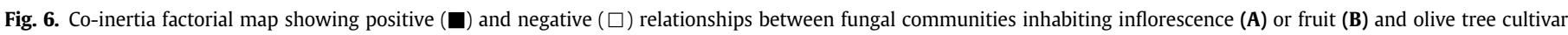

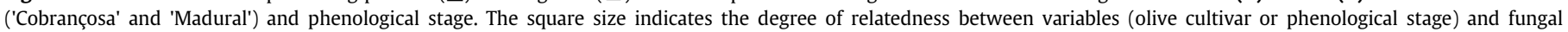
community. Host phenological stage includes inflorescence development (D, E), flowering (F, G), and fruit ripening (MI 2, MI 3, MI 4 ). For more details see Fig. 1.

2013), in particular at the level of reproductive organs (Aleklett et al., 2014). These mechanisms might be associated with phenotypic properties, such as morphology, chemistry and physiology (Lemanceau et al., 2017), and immune system (Saunders and Kohn, 2009) of the host plant. Here, the anthracnose-resistant cultivar
'Cobrançosa' seems to be able to prevent the invasion and colonization of inflorescences by fungal endophytes when compared to the anthracnose-susceptible cultivar 'Madural', because of the higher fungal colonization rate observed in the latter cultivar. Thus, differences in anthracnose-susceptibility among the two surveyed 
cultivars are likely to play a role in the structure of fungal endophytic communities of inflorescences. However, the effect of olive cultivar on fungal assemblage differed among reproductive organs. In contrast to inflorescence, the fruit-associated fungal community assemblage was not influenced by the olive cultivar. Thus, it is possible that host plant effects may vary due to the influence of other factors, such as environmental variables, as previously suggested by Wagner et al. (2016).

Endophytic fungal abundance and diversity were higher in inflorescences than in fruits. Few studies have directly compared the endophytic fungal communities of flowers with those of other parts of the same plant. In olive trees, Abdelfattah et al. (2015) found a higher fungal population in flowers than in fruits, as observed in our study. This result may be related to differences in the chemical composition of the two organs. Olive fruits are rich in phenol compounds (Gouvinhas et al., 2017), which have antimicrobial activity (Marković et al., 2019) and which could prevent the colonization of fruits by fungi. In contrast, flowers are reported to be a nutrient-rich environment for fungi (Aleklett et al., 2014). In particular, flower stigmas exude sugars and amino acids creating a wet and sticky environment (Aleklett et al., 2014), and thus it is likely that they support a relatively large fungal load compared to that of other plant organs. In fact, the variation partitioning analysis showed that the composition of the fungal community of the reproductive organs was primarily impacted by plant organ.

Both abundance and richness of fungal endophytes were higher in open flowers than in closed ones. This is probably due to the higher exposure to the environment or to the greater nutritional resources for fungal colonization of open flowers than for closed ones. Moreover, in comparison to closed flowers, the open ones received more pollinator visits and pollen grains that can carry fungi to the flower as discussed in Aleklett et al. (2014). It is also plausible that the lack of lignin in petal cell walls make the open flowers more easily colonized by endophytic fungi than the closed ones, where the petals overlap one another. There was a group of fungal genera positively associated with flowers when opened, Tricharina spp. being the most significant. The genus Tricharina belongs to the class Pezizomycetes, which occurs in a broad range of habitats, including soil, decaying wood and plants, acting as saprobes, mycorrhizas or endophytes (Hansen et al., 2013). According to Rodriguez et al. (2009) the Pezizomycetes are class 3 endophytes, which are horizontally transmitted by spores and hyphal fragments from plant to plant, by biotic or abiotic dispersal agents. Thus, we hypothesized that Tricharina spp. colonizing open olive tree flowers probably came from the surrounding environment. After opening, the fungal abundance and richness of flowers decreased to petal fall, suggesting that only some of the fungi that migrate to the flower were able to successfully grow and persist in it. Cladosporium spp. was strongly positively associated with flowers after the loss of petals. Cladosporium species are ubiquitous worldwide, being frequently isolated from air, soil and plants (Seifert et al., 2011). Although these fungi are considered to be saprotrophic, some species are endophytes or pathogens of various plant hosts (Seifert et al., 2011).

In the present study, differences in fungal community structure were detected across fruit ripening, fungal abundance and richness being higher in ripe olives than in unripe ones. This may be due to phenol content decrease during ripening (Gouvinhas et al., 2017), making the fruit more favorable for fungal colonization and growth. Pyrenochaeta was the genus most associated with unripe fruits (MI 2 ). Some species of this genus are plant pathogens (Aragona et al., 2014). Ripe fruits (MI 3 and 4) were positively associated with fungal genera which included species described to be beneficial as effective biological control agents or phytopathogenic to several host plants (Coniothyrium; Verkley et al., 2014), including of olive trees (Pseudophaeomoniella; Antelmi et al., 2018), or toxigenic (Aspergillus; Abdel-Azeem et al., 2016).

A set of fungal genera and species were specific to a particular cultivar, suggesting that they might be relevant to olive tree health. Otherwise, these fungi would not continue to be highly associated with these different olive cultivars. The fungi most associated with and/or indicative of anthracnose-susceptible cultivar are pathogens of olive trees (Colletotrichum spp. and Neofabraea cf. vagabunda) causing fruit rot diseases (Cacciola et al., 2012; Romero et al., 2016), or are common pathogens of other plant species, such as Diaporthe spp. (Guarnaccia et al., 2018), Alternaria spp. (Troncoso-Rojas and Tiznado-Hernández, 2014), Biscogniauxia spp. (Nugent et al., 2005), Botrytis spp. (Williamson et al., 2007) and Stemphylium spp. (Hanse et al., 2015). Tricharina sp. MF20 has been reported to offer benefits to their host plants (Hansen et al., 2013). The most anthracnose-resistant cultivar also had several indicator/positively associated fungal genera, some of them being described as beneficial to plants as biological control agents, such as Paraconiothyrium spp. (Verkley et al., 2004), but also one phytopathogen recently described to infect olive trees (Fusarium aff. solani; Chliyeh et al., 2017). Other fungi associated with cv. 'Cobrançosa' were Aspergillus spp., which include both pathogenic and beneficial species (Abdel-Azeem et al., 2016), and Ochrocladosporium spp. with unknown biological function. Interestingly, Colletotrichum spp. were not isolated from cv. 'Cobrançosa', suggesting that they cannot thrive so well as in the cv. 'Madural'. We hypothesize that differences in endophytic fungal assemblage composition among cultivars could have important consequences for Colletotrichum spp. colonization. Interactions between members of the fungal community of cv. 'Cobrançosa' is more likely to prevent Colletotrichum spp. colonization than in cv. 'Madural'. Further research is needed to confirm this suggestion.

In our study, all the fungal isolates were recovered from symptomless inflorescences and fruits. Among these fungi, common olive pathogens (e.g., Colletotrichum spp. and Neofabraea spp.) were identified, suggesting that they may have an endophytic or latent infection period during flower and fruit development. Other fungal pathogens non-specific to olive trees, were also isolated as endophytes, making the distinction between an endophyte and a pathogen unclear. The most widely accepted definition of endophytes was proposed by Petrini (1991) who considered endophytes as all organisms that inhabit internal plant tissues during all or part of their life cycle without causing any disease symptoms. Because of the presence of multiple lifestyles in endophytes, more recently, definitions considered endophytes as microorganisms that colonize the plant interior regardless of the outcome of the association (Hardoim et al., 2015).

\section{Conclusion}

The endophytic fungal communities of olive tree were primarily impacted by plant organ and phenological stage, and to a lesser extent by olive cultivar. Indeed, olive cultivar effects on fungal community composition were seen only in inflorescences. This organ also harbored a greater diversity and abundance of fungal endophytes than fruits. Although olive cultivar only had a small effect on endophytic fungal assemblage, specific fungal taxa and genera were associated with each olive cultivar/plant organ/ phenological stage. For instance, Colletotrichum spp. was positively associated with the inflorescences and fruits of the anthracnosesusceptible cultivar, while in the anthracnose-resistant cultivar this genus was not found. Moreover, assessing the lifestyle of the fungi positively associated with and/or indicative of the two cultivars revealed a higher number of plant beneficial fungi or fungi with unknown biological function in the anthracnose-resistant 
cultivar than in the susceptible ones. Taken together, our results suggest that specific fungal interactions occurring in the endophytic community of the two cultivars are likely to affect the colonization of inflorescences and fruits by Colletotrichum spp.The role of these beneficial fungi in olive tree resistance to anthracnose disease is a topic that requires further research. In particular, studies of the interactions between these fungi, olive trees and the pathogen Colletotrichum spp. will likely reveal the functional roles of these fungal endophytes in host susceptibility/resistance to anthracnose disease.

\section{Declaration of competing interest}

The authors declare no conflict of interest.

\section{Acknowledgements}

This work is supported by FEDER funds through the COMPETE (Operational Programme for Competitiveness Factors) and by the Foundation for Science and Technology (FCT, Portugal) within the POCI-01-0145-FEDER-031133 (MicOlives) project and FCT/MCTES to CIMO (UIDB/00690/2020). F. Martins thanks the award of a PhD scholarship (ref. SFRH/BD/112234/2015) by FCT.

\section{Supplementary data}

Supplementary data to this article can be found online at https://doi.org/10.1016/j.funeco.2020.101003.

\section{References}

Abdel-Azeem, A.M., Salem, F.M., Abdel-Azeem, M.A., Nafady, N.A., Mohesien, M.T., Soliman, E.A., 2016. Biodiversity of the genus Aspergillus in different habitats. In: Gupta, V.K. (Ed.), New and Future Developments in Microbial Biotechnology and Bioengineering: Aspergillus System Properties and Applications. Elsevier, Amsterdam, pp. 3-28.

Abdelfattah, A., Nicosia, M.G.L.D., Cacciola, S.O., Droby, S., Schena, L., 2015. Metabarcoding analysis of fungal diversity in the phyllosphere and carposphere of olive (Olea europaea). PloS One 10 (7), e0131069.

Aleklett, K., Hart, M., Shade, A., 2014. The microbial ecology of flowers: an emerging frontier in phyllosphere research. Botany 92, 253-266.

Antelmi, I., Ferrara, M., Sion, V., Mule, G., Nigro, F., 2018. Genomic characterization of Pseudophaemoniella species occurring in the sap wood of healthy and diseased olive trees affected by quick decline syndrome. In: European Research on Emerging Plant Diseases. Contributions of the H2020 Projects POnTE and XFACTORS 2nd Joint Annual Meeting, Book of Abstracts, Valencia (Spain), pp. 23-26 (October).

Aragona, M., Minio, A., Ferrarini, A., Valente, M.T., Bagnaresi, P., Orrù, L., Tononi, P., Zamperin, G., Infantino, A., Valè, G., Cattivelli, L., Delledonne, M., 2014. De novo genome assembly of the soil-borne fungus and tomato pathogen Pyrenochaeta lycopersici. BMC Genom. 15, 313.

Bálint, M., Tiffin, P., Hallstrom, B., O'Hara, R.B., Olson, M.S., Fankhauser, J.D., Piepenbring, M., Schmitt, I., 2013. Host genotype shapes the foliar fungal microbiome of balsam poplar (Populus balsamifera). PloS One 8 (1), e53987.

Berendsen, R.L., Pieterse, C.M.J., Bakker, P.A.H.M., 2012. The rhizosphere microbiome and plant health. Trends Plant Sci. 17, 478-486.

Bray, J.R., Curtis, J.T., 1957. An ordination of upland forest communities of southern Wisconsin. Ecol. Monogr. 27, 325-349.

Cacciola, S.A., Faedda, R., Sinatra, F., Agosteo, G.E., Schena, L., Frisullo, S., di San Lio, M.G., 2012. Olive anthracnose. J. Plant Pathol. 94, 29-44.

Cáceres, M., Legendre, P., Wiser, S.K., Brotons, L., 2012. Using species combinations in indicator value analyses. Methods Ecol. Evol. 3, 973-982.

Chliyeh, M., Msairi, S., Touhami, A.O., Benkirane, R., Douira, A., 2017. Detection of Fusarium solani as a pathogen causing root rot and wilt diseases of young olive trees in Morocco. Annu. Res. Rev. Biol. 13, 1-7.

Compant, S., Saikkonen, K., Mitter, B., Campisano, A., Mercado-Blanco, J., 2016. Editorial special issue: soil, plants and endophytes. Plant Soil 405, 1-11.

Dissanayake, A.J., Purahong, W., Wubet, T., Hyde, K.D., Zhang, W., Xu, H., Zhang, G., Fu, C., Liu, M., Xing, O., Li, X., Yan, J., 2018. Direct comparison of culturedependent and culture-independent molecular approaches reveal the diversity of fungal endophytic communities in stems of grapevine (Vitis vinifera). Fungal Divers. 90, 85-107.

Dray, S., Dufour, A., 2007. The ade4 package: implementing the duality diagram for ecologists. J. Stat. Software 22, 1-20.

Dufrêne, M., Legendre, P., 1997. Species assemblages and indicator species: the need for a flexible asymmetrical approach. Ecol. Monogr. 67, 345-366.

Gomes, T., Pereira, J.A., Benhadi, J., Lino-Neto, T., Baptista, P., 2018. Endophytic and epiphytic phyllosphere fungal communities are shaped by different environmental factors in a Mediterranean ecosystem. Microb. Ecol. 76, 668-679.

Gouvinhas, I., Domínguez-Perles, R., Gironés-Vilaplana, A., Carvalho, T., Machado, N., Barros, A., 2017. Kinetics of the polyphenolic content and radical scavenging capacity in olives through on-tree ripenings. J. Chem. 11, 2017, ID 5197613.

Guarnaccia, V., Groenewald, J.Z., Woodhall, J., Armengol, J., Cinelli, T., Eichmeier, A. Ezra, D., Fontaine, F., Gramaje, D., Gutierrez-Aguirregabiria, A., Kaliterna, J., Kiss, L., Larignon, P., Luque, J., Mugnai, L., Naor, V., Raposo, R., Sándor, E., Váczy, K.Z., Crous, P.W., 2018. Diaporthe diversity and pathogenicity revealed from a broad survey of grapevine diseases in Europe. Persoonia 40, 135-153.

Hanse, B., Raaijmakers, E.E.M., Schoone, A.H.L., 2015. Stemphylium sp., the cause of yellow leaf spot disease in sugar beet (Beta vulgaris L.) in The Netherlands. Eur. J. Plant Pathol. 141, 1-12.

Hansen, K., Perry, B.A., Dranginis, A.W., Pfister, D.H., 2013. A phylogeny of the highly diverse cup-fungus family Pyronemataceae (Pezizomycetes, Ascomycota) clarifies relationships and evolution of selected life history traits. Mol. Phylogenet. Evol. 67, 311-335.

Hardoim, P.R., van Overbeek, L.S., Berg, G., Pirttiläd, A.M., Compant, S., Andrea Campisano, A., Döring, M., Sessitsch, A., 2015. The hidden world within plants: ecological and evolutionary considerations for defining functioning of microbial endophytes. Microbiol. Mol. Biol. Rev. 79, 293-320.

Hermoso, M., Uceda, M., Frias, L., Beltrán, G., 2001. Maduración. In: Barranco, D., Fernández-Escobar, R., Rallo, L. (Eds.), El Cultivo Del Olivo $4^{\mathrm{a}}$ Edicion. Ediciones Mundi-Prensa, Madrid, pp. 153-170.

IOC - International Olive Council, 2019. Newsletter International Olive Council. $\mathrm{N}^{\circ}$ 144. https://www.internationaloliveoil.org/wp-content/uploads/2019/12/ NEWSLETTER_144_ENGLISH.pdf.

Khare, E., Mishra, J., Arora, N.K., 2018. Multifaceted interactions between endophytes and plant: developments and prospects. Front. Microbiol. 9, 2732.

Lemanceau, P., Barret, M., Mazurier, S., Mondy, S., Pivato, B., Fort, T., Vacher, C., 2017. Plant communication with associated microbiota in the spermosphere, rhizosphere and phyllosphere. Adv. Bot. Res. 82, 101-133.

Malavolta, C., Perdikis, D., 2018. Crop specific technical guidelines for integrated production of olives. IOBC-WPRS Commission IP Guidelines, 4nd Edition 77, $1-19$.

Marković, A.K., Torić, J., Barbaric, M., Brala, C.J., 2019. Hydroxytyrosol, tyrosol and derivatives and their potential effects on human health. Molecules 10, 2001.

Moral, J., Xaviér, C.J., Viruega, J.R., Roca, L.F., Caballero, J., Trapero, A., 2017. Variability in susceptibility to anthracnose in the world collection of olive cultivars of Cordoba (Spain). Front. Plant Sci. 8, 1892.

Moricca, S., Ginetti, B., Ragazzi, A., 2012. Species- and organ-specificity in endophytes colonizing healthy and declining Mediterranean oaks. Phytopathol. Mediterr. 3, 587-598.

Nugent, L.K., Sihanonth, P., Thienhirun, S., Whalley, A.J.S., 2005. Biscogniauxia: a genus of latent invaders. Mycologist 19, 40-43.

Oksanen, J., Blanchet, F.G., Friendly, M., Kindt, R., Legendre, P., McGlinn, D., Minchin, P.R., O'Hara, R.B., Simpson, G.L., Solymos, P., Stevens, H.H., Szoecs, E., Wagner, H., 2018. Vegan: community ecology package. R Package Version 2, pp. $3-5$.

Petrini, O., 1991. Fungal endophytes of tree leaves. In: Andrews, J.A., Hirano, S.S. (Eds.), Microbial Ecology of Leaves. Springer-Verlag, New York, pp. 179-197.

Qian, X., Duan, T., Sun, X., Zheng, Y., Wang, Y., Hu, M., Yao, H., Ji, N., Lv, P., Chen, L., Shi, M., Guo, L., Zhang, D., 2018. Host genotype strongly influences phyllosphere fungal communities associated with Mussaenda pubescens var. alba (Rubiaceae). Fungal Ecol 36, 141-151.

R Core Team, 2018. R: a Language and Environment for Statistical Computing. $\mathrm{R}$ Foundation for Statistical Computing, Vienna, Austria. URL:, Version 3.5.1. http://www.R-project.org.

Ren, F., Dong, W., Yan, D.H., 2019. Organs, cultivars, soil, and fruit properties affect structure of endophytic mycobiota of Pinggu peach trees. Microorganisms 7, 322.

Rodriguez, R.J., White Jr., J.F., Arnold, E.A., Redman, R.S., 2009. Fungal endophytes: diversity and functional roles. New Phytol. 182, 314-330.

Romero, J., Raya, M.C., Roca, L.F., Moral, J., Trapero, A., 2016. First report of Neofabraea vagabunda causing branch cankers on olives in Spain. Plant Dis. 100, 527.

Sanz-Cortés, F., Martínez-Calvo, J., Badenes, M.L., Bleiholder, H., Hack, H., Llácer, G., Meier, U., 2002. Phenological growth stages of olive trees (Olea europaea). Ann. Appl. Biol. 140, 151-157.

Saunders, M., Kohn, L.M.M., 2009. Evidence for alteration of fungal endophyte community assembly by host defense compounds. New Phytol. 182, 229-238.

Seaby, R.M.H., Henderson, P.A., 2014. Community Analysis Package Version 5. Pisces Conservation Ltd, Lymington, UK.

Seaby, R.M., Henderson, P.A., 2006. Species Diversity and Richness Version 4. Pisces Conservation Ltd, Lymington, England.

Seifert, K., Morgan-Jones, G., Gams, W., Kendrick, B., 2011. The Genera of Hyphomycetes. CBS Biodiversity Series No. 9: 1-997. CBS-KNAW Fungal Biodiversity Centre, Utrecht, Netherlands.

Sergeeva, V., Spooner-Hart, R., Nair, N., 2008. Evidence of early flower infection in olives (Olea europaea) by Colletotrichum acutatum and C. gloeosporioides causing anthracnose disease. Australas. Plant Dis. Notes 3, 81-82.

Singh, P., Gobbi, A., Santoni, S., Hansen, L.H., This, P., Péros, J.P., 2018. Assessing the impact of plant genetic diversity in shaping the microbial community structure 
of Vitis vinifera phyllosphere in the Mediterranean. Front. Life Sci. 1, 35-46. Troncoso-Rojas, R., Tiznado-Hernández, M.E., 2014. Alternaria alternata (black rot, black spot). In: Bautista-Baños, S. (Ed.), Postharvest Decay - Control Strategies. Academic Press, New York, pp. 147-187.

Verkley, G.J.M., Duki, K., Renfurm, R., Göker, M., Stielow, J.B., 2014. Novel genera and species of coniothyrium-like fungi in Montagnulaceae (Ascomycota). Persoonia $32,25-51$.

Verkley, G.J.M., Silva, M. da, Wicklow, D.T., Crous, P.W., 2004. Paraconiothyrium, a new genus to accommodate the mycoparasite Coniothyrium minitans, anamorphs of Paraphaeosphaeria, and four new species. Stud. Mycol. 50, 323-335.

Vu, D., Groenewald, M., de Vries, M., Gehrmann, T., Stielow, B., Eberhardt, U., AlHatmi, A., Groenewald, J.Z., Cardinali, G., Houbraken, J., Boekhout, T., Crous, P.W., Robert, V., Verkley, G.J.M., 2019. Large-scale generation and analysis of filamentous fungal DNA barcodes boosts coverage for kingdom fungi and reveals thresholds for fungal species and higher taxon delimitation. Stud. Mycol. 92, 135-154.

Wagner, M.R., Lundberg, D.S., Del Rio, T.G., Tringe, S.G., Dangl, J.L., Mitchell-Olds, T.,
2016. Host genotype and age shape the leaf and root microbiomes of a wild perennial plant. Nat. Commun. 7, 12151.

White, T., Bruns, T., Lee, S., Taylor, J., 1990. Amplification and direct sequencing of fungal ribosomal RNA genes for phylogenetics. In: Innis, M.A., Gelfand, D.H., Sninsky, J.J., White, T.J. (Eds.), PCR Protocols: a Guide to Methods and Applications. Academic Press, New York, pp. 315-322.

Williamson, B., Tudzynski, B., Tudzynski, P., van Kan, J.A., 2007. Botrytis cinerea: the cause of grey mould disease. Mol. Plant Pathol. 8, 561-580.

Wu, B., Hussain, M., Zhang, W., Stadler, M., Liu, X., Xiang, M., 2019. Current insights into fungal species diversity and perspective on naming the environmental DNA sequences of fungi. Mycology 10, 127-140.

Zhang, Y., Yu, X., Zhang, W., Lang, D., Zhang, X., Cui, G., Zhang, X., 2019. Interactions between endophytes and plants: beneficial effect of endophytes to ameliorate biotic and abiotic stresses in plants. J. Plant Biol. 62, 1-13.

Zuur, A.F., Ieno, E.N., Walker, N.J., Saveliev, A.A., Smith, G.M., 2009. Mixed Effect Models and Extensions in Ecology with R. Springer-Verlag, New York. 